\title{
Universiteit
}

Leiden

The Netherlands

\section{C NMR study of the grafting of maleic anhydride onto polyethene, polypropene, and ethene-propene copolymers}

Heinen, W.; Rosenmöller, C.H.; Wenzel, C.B.; Groot, H.J.M. de; Lugtenburg, J.; Duin, M. van

\section{Citation}

Heinen, W., Rosenmöller, C. H., Wenzel, C. B., Groot, H. J. M. de, Lugtenburg, J., \& Duin, M. van. (1996). 13C NMR study of the grafting of maleic anhydride onto polyethene, polypropene, and ethene-propene copolymers. Macromolecules, 29(4), 1151-1157. doi:10.1021/ma951015y

Version: $\quad$ Publisher's Version

License: $\quad$ Licensed under Article 25fa Copyright Act/Law (Amendment Taverne)

Downloaded from: https://hdl.handle.net/1887/3238827

Note: To cite this publication please use the final published version (if applicable). 


\title{
${ }^{13} \mathrm{C}$ NMR Study of the Grafting of Maleic Anhydride onto Polyethene, Polypropene, and Ethene-Propene Copolymers
}

\author{
W. Heinen, C. H. Rosenmbller, C. B. Wenzel, H. J . M. de Groot,* and \\ J . Lugtenburg \\ Leiden Institute of Chemistry, Gorlaeus Laboratories, P.O. Box 9502, 2300 RA Leiden, \\ The Netherlands
}

\section{M. van Duin}

DSM Research, P.O. Box 18, 6160 MD Geleen, The Netherlands

Received J uly 14, 1995; Revised Manuscript Received November 7, $1995^{\circledR}$

\begin{abstract}
The reaction products from the radically initiated grafting of specifically ${ }^{13} \mathrm{C}$-enriched maleic anhydride $\left(\left[2,3-{ }^{13} \mathrm{C}_{2}\right] \mathrm{MA}\right)$ onto polyethene, isotactic polypropene and ethene-propene copolymers in the melt and in solution are investigated using noise-decoupled and $1 D$ inadequate ${ }^{13} \mathrm{C}$ NMR spectroscopy. The sites of attachment and the structures of the grafts depend on (co)polymer composition. In random EPM, MA attaches to methylene and methine carbons in the backbone. In alternating EPM, MA attaches solely to polymer methines, indicating that $\left(\mathrm{CH}_{2}\right)_{\mathrm{m}}$ sequences with $\mathrm{m}>3$ are needed for MA attachment to backbone methylene carbons. In the copol ymers and in IPP, grafts are single succinic anhydride rings; in HDPE and LDPE short MA oligomers arealso present. In polyol efins containing polypropene sequences, chain scission can yield structures in which the anhydride ring is attached to the chain terminus via a fully substituted double bond.
\end{abstract}

\section{Introduction}

Polyol efins functionalized with maleic anhydride (MA) exhibit enhanced adhesion to polar materials like polyamide, metals, and glass and are used as compatibilizing agents. For instance, the improvement of impact properties upon blending of polyamide- 6 with various maleated polyolefins is associated with the formation of a polyamide-polyolefin graft copolymer in situ during melt blending ${ }^{1-5}$ The functionalization of polyolefins with MA can be achieved in a melt process where the molten polymer is mixed with MA and an initiator, such as a suitable peroxide, in an extruder at elevated temperatures. ${ }^{6-10}$ Alternatively, in a solution process, the polymer is dissolved in a suitable solvent at elevated temperatures, and MA is added together with a suitable initiator. ${ }^{9,11-13}$ It is generally thought that the grafting reaction involves initiation by abstraction of hydrogen atoms from the polymer chain by (initiator) radicals and addition of the unsaturated monomer to macroradicals. ${ }^{6-9,13}$

The performance of adhesion and compatibilization of polyol efins functionalized with MA can be expected to depend on the microstructure of the graft copolymer and detailed knowledge of it is important for understanding structure-properties relationships for these graft copolymers. In polyolefins several structurally different radical sites can be produced by the action of radical initiators. The predominantly secondary and tertiary macroradicals have different reactivities toward MA. ${ }^{14}$ In polyethene (PE) there are almost exclusively methylene carbons present, while in isotactic polypropene (iPP) each repetitive unit provides three possible grafting sites: the methyl, the methylene, and the methine. In randomly polymerized ethene-propene copolymers (EPMs) there is a multitude of chemically different sites. Finally, one can distinguish the carbon atoms close to or at the chain termini, but these sites are rare in high polymers. In addition, various side

\footnotetext{
$\otimes$ Abstract published in Advance ACS Abstracts, J anuary 15, 1996.
}

reactions may occur during radically initiated grafting. It is generally accepted that cross-linking in PE and chain scission in PP may occur simultaneously with the graft reaction. ${ }^{15}$ EPMs may undergo both side reactions. ${ }^{15}$ Besides the exact site of attachment, an additional item that has been speculated upon is the structure of the MA graft. A single, saturated succinic anhydride graft is usually suggested, $, 12,13,16$ but unsaturated, ${ }^{8}$ ol igomeric, ${ }^{7,8}$ polymeric grafts, ${ }^{17}$ and a combination of single and oligomeric grafts ${ }^{18}$ have also been proposed.

The aims of this investigation are to elucidate the molecular structure of MA grafted PE, iPP, and EPMS and to characterize the mechanism of the peroxide initiated grafting. Genuine, essentially unperturbed materials are investigated using site specific isotope labeling and NMR spectroscopy. First, EPMs with varying propene contents, PE, and PP have been used as substrates in melt-grafting reactions to study the effect of (co)polymer composition on the chemistry of grafting. Subsequently, a selection of these materials was reacted with MA in a solution process to compare the two methods of functionalization.

Site specific isotopic enrichment with $99 \%{ }^{13} \mathrm{C}$ can be used to enhance the intensities of NMR signals of functionalities that are present in small amounts only. ${ }^{19}$ Earlier, Glans and Akkapeddi ${ }^{20}$ used $\left[2,3-{ }^{13} \mathrm{C}_{2}\right] \mathrm{MA}$ to investigate the molecular structure of MA-grafted poly(2,6-dimethylphenylene ether). MA is a symmetric molecule and it is of advantage to label both olefin carbons that constitute the possible sites of attachment to the polymer chain. Furthermore, incorporation of adjacent ${ }^{13} \mathrm{C}$ labels allows the application of multiple quantum filtering techniques to separate the label signals from the natural abundance background.

\section{Experimental Section}

$\left[2,3-{ }^{13} \mathrm{C}_{2}\right] \mathrm{MA}$ was synthesized starting from $\left[2-{ }^{13} \mathrm{C}\right.$ ]acetic acid (Cambridge Isotopes Laboratories, 99\% enriched). This was first converted to ethyl bromo[2-13 C]acetate via the HellVollhard-Zelinsky reaction. (Carboethoxy $\left[{ }^{13} \mathrm{C}\right]$ methyl)triphenylphosphonium bromide was prepared by treating the ethyl 
bromoacetate with triphenylphosphine. The Wittig salt thus obtained was deprotonated and coupled oxidatively in the presence of 0.5 equiv of triphenyl phosphite-ozone adduct to yield $\left[2,3-{ }^{13} \mathrm{C}_{2}\right]$ diethyl fumarate. ${ }^{21}$ This is hydrolyzed by refluxing in concentrated hydrochloric acid. The resulting [2,3${ }^{13} \mathrm{C}_{2}$ ]fumaric acid is isomerized and dehydrated to give [2,3${ }^{13} \mathrm{C}_{2}$ ]MA (approximately $98 \%$ doubly labeled) by heating in the presence of phosphorus pentoxide. The overall yield is $44 \%$ based on acetic acid. NMR and mass spectrometry did not reveal any significant dilution or scrambling of the labels. Full experimental details and spectral identification will be presented in a forthcoming publication.

The polymers used are HDPE (DSM, essentially linear), LDPE (DSM, containing 25 wt \% octene), EPM (random, 66 wt \% E, E:P 3:1), EPM (random, 57 wt \% E, E:P 2:1), alt-EPM (hydrogenated natural rubber, E:P 1:1), EPM ASTM 1 (random, 40 wt \% E, E:P 1:1), BASF 2900NCX (random, 18 wt \% E, E:P 1:3) (E denotes ethene, $P$ propene), and isotactic PP (DSM). MA was grafted in a home-built, small scale, fully intermeshing, conical, corotating twin screw extruder with a recirculation channel, allowing its use as a batch reactor, with a capacity of $5 \mathrm{~g}$. The temperature is monitored with a thermocouple within the steel casing and can be controlled within 2 deg. The materials were rapidly ejected from the reaction chamber by opening a release valve. Mixtures with compositions typical for industrial recipes ${ }^{10}$ were reactively extruded for $5 \mathrm{~min}$ with the screw rotation speed set at $\sim 100 \mathrm{rpm}$ and the temperature at $170{ }^{\circ} \mathrm{C}$. In a typical melt-grafting experiment $3.5 \mathrm{~g}$ of granular (co)polymer was premixed with 5 wt \% powdered [2,3${ }^{13} \mathrm{C}_{2}$ ]MA and 0.25 wt \% liquid tert-butyl cumyl peroxide (Trigonox T, Akzo Nobel) as the radical initiator and dosed via a hopper into the preheated miniextruder. No special precautions were taken to exclude air from the mixing chamber. The products typically had a beige-like appearance when they were ejected from the miniextruder. After the reactive extrusion unreacted $M A$ and other volatiles were removed by heating the product for $1 \mathrm{~h}$ at $180^{\circ} \mathrm{C}$ in vacuo.

In the solution-grafting experiments $1 \mathrm{~g}$ of either HDPE, iPP, alt-EPM, or EPM ASTM 1 was dissolved in $5 \mathrm{~g}$ of biphenyl at $170^{\circ} \mathrm{C}$ under a nitrogen atmosphere. Biphenyl was taken as reaction medium since it does not contain benzylic hydrogen atoms that may be involved in undesired reactions with the MA. ${ }^{22,23}$ After complete dissolution of the polymer, $100 \mathrm{mg}$ of $\left[2,3-{ }^{13} \mathrm{C}_{2}\right] \mathrm{MA}$ and $100 \mathrm{mg}$ of di-tert-butyl peroxide radical initiator (Aldrich) were added. After $1 \mathrm{~h}$ the reaction mixture was poured out into $50 \mathrm{~mL}$ of acetone to precipitate the grafted polymer. The product was washed thoroughly with boiling acetone and subsequently dried in vacuo at $60{ }^{\circ} \mathrm{C}$. The ditert-butyl peroxide has a longer half-life compared to tert-butyl cumyl peroxide, the initiator used in the melt procedure, to suit the longer reaction time.

Samples for NMR spectroscopy were prepared by dissol ving about $180 \mathrm{mg}$ of product in $\sim 3 \mathrm{~mL}$ of deuterated 1,1,2,2tetrachloroethane (Merck) in a $10 \mathrm{~mm}$ NMR tube. ${ }^{13} \mathrm{C}$ NMR spectra were recorded with a Bruker MSL 400 spectrometer at a temperature of $120^{\circ} \mathrm{C}$. The spectra are referenced relative to TMS using the solvent signal as an internal standard. In various samples, $\mathrm{T}_{1} \mathrm{~s}$ were determined or estimated to choose the appropriate recycle delay for the data acquisition. Noisedecoupled spectra were obtained using a short "tip" pulse and a recycle time of $2 \mathrm{~s}$. 1D inadequate ${ }^{24}$ experiments were optimized for $\mathrm{J} \mathrm{C}-\mathrm{C}=34 \mathrm{~Hz}$ and spectra were acquired with a recycle time of $3 \mathrm{~s}$, which is equal to 5 times the $T_{1}$ of the labeled carbon atoms. The ${ }^{13} \mathrm{C}-{ }^{1} \mathrm{H}$ 2D-J -resolved spectrum was recorded using the gated decoupling technique.

Peak areas are estimated from the noise-decoupled spectra only. To estimate the average lengths of the grafts for HDPEg-MA and LDPE-g-MA, label signals were integrated between $\delta=30.2$ and $32.2 \mathrm{ppm}$ for the methylene carbons, and between $\delta=43.0$ and $45.3 \mathrm{ppm}$ for the methine carbons, which corresponds to the widths of the respective inadequate re sponses. Before integration, the backgrounds were estimated and subtracted from the data. The NOE enhancement efficiencies for the labeled methine and methylene responses were assumed equal, since in the noise-decoupled spectrum of alt-EPM-g-[2,3-13 $\left.\mathrm{C}_{2}\right] \mathrm{MA}$, containing only single anhydride grafts, integrated intensities are equal within experimental

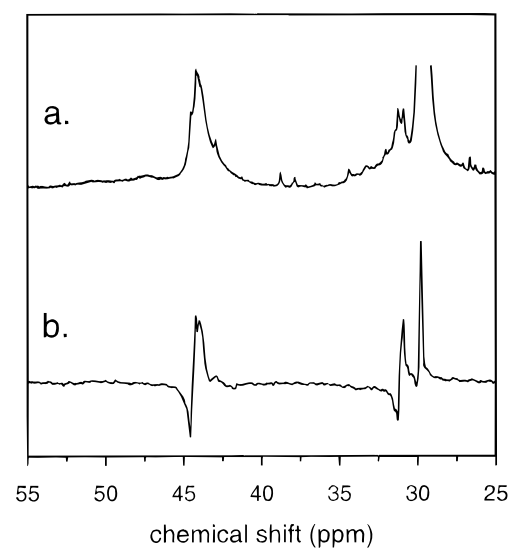

Figure 1. Aliphatic part of (a) the noise-decoupled ${ }^{13} \mathrm{C} N \mathrm{NR}$ spectrum of HDPE grafted with $\left[2,3-{ }^{13} \mathrm{C}_{2}\right] \mathrm{MA}$ (the large backbone resonance at $\delta=29.8 \mathrm{ppm}$ is truncated) and (b) the 1D inadequate spectrum of the same material, in which the natural abundance resonance of the polymer chain is strongly reduced.

error. In the noise-decoupled spectra other than those from the PE-g-MA's, the signals from the ${ }^{13} \mathrm{C}$-enriched sites are rather small relative to those from natural abundance sites and there is severe overlap between labeled and natural abundance signals; therefore average graft lengths could not be estimated for these materials.

\section{Results and Discussion}

All polyolefins investigated in this study are grafted in a small scale extruder. This mimics actual industrial processes ${ }^{10}$ accurately, and optimally with respect to the amount of expensive labeled material needed, allowing the investigation of the grafting process with atomic resolution without any disturbance from reaction conditions or workup.

Structure of PE-g-MA. The top trace in Figure 1 shows the aliphatic part of the noise-decoupled ${ }^{13} \mathrm{C}$ spectrum of HDPE grafted with $\left[2,3-{ }^{13} \mathrm{C}_{2}\right] \mathrm{MA}$ in the melt at $170{ }^{\circ} \mathrm{C}$ with tert-butyl cumyl peroxide as the initiator. By comparison of this spectrum to that of HDPE grafted under identical conditions with unlabeled MA (data not shown) it is evident that the strong (truncated) signal at $\delta=29.8 \mathrm{ppm}$ is the natural abundance background of the HDPE backbone, while the signals at $\delta=31.1$ and 44.3 ppm are associated with the labels in the MA grafts. The 1D inadequate response of the same sample (F igure 1b) provides conclusive evidence for this assignment, since the natural abundance signal is strongly suppressed, while the adjacent labels give rise to large antiphase signals typical for this type of experiment. A splitting of $\sim 34 \mathrm{~Hz}$ of the high-field label signal is observed, which is typical for a $\mathrm{sp}^{3}-\mathrm{sp}^{3}{ }^{13} \mathrm{C}-{ }^{13} \mathrm{C}$ onebond J coupling. ${ }^{25}$ On the left hand side of the broad low-field signal small peaks separated by $\sim 34 \mathrm{~Hz}$ can be distinguished. These signals are the doublet pairs of an $A B$ spin system, which is expected as the labeled positions in $\left[2,3-{ }^{13} C_{2}\right] \mathrm{MA}$ become inequivalent upon attachment of MA to the polymer chain as a single succinic anhydride unit. The chemical shifts of the resonances from the labels match that of the methylene $(\delta=29.7 \mathrm{ppm})$ and the methine $(\delta=43.2 \mathrm{ppm})$ in the anhydride ring of the model compound hept- $4^{\prime}$-yl succinic anhydride. ${ }^{26}$ The integrated response of the methines (in Figure la at $\delta=44.3 \mathrm{ppm}$ ) is larger than the signal from the methylenes ( $\delta=31.0 \mathrm{ppm})$. The width of the methine resonance and its larger area with respect to the methylene signal reveal the presence of grafted MA dimers or possibly even larger oligomers. In such graft structures there are $2(n+1)$ adjacent ${ }^{13} \mathrm{C}$ labels of 
Table ${ }^{1}{ }^{13} \mathrm{C}$ Chemical Shifts of the Methylene and Methine Carbons in the Anhydride Ring of MA-Grafted Polyolefins, the ${ }^{13} \mathrm{C}^{13} \mathrm{C}^{1 \mathrm{~J}}$ Coupling Constants between These Carbon Atoms, and the Associated Graft Structures

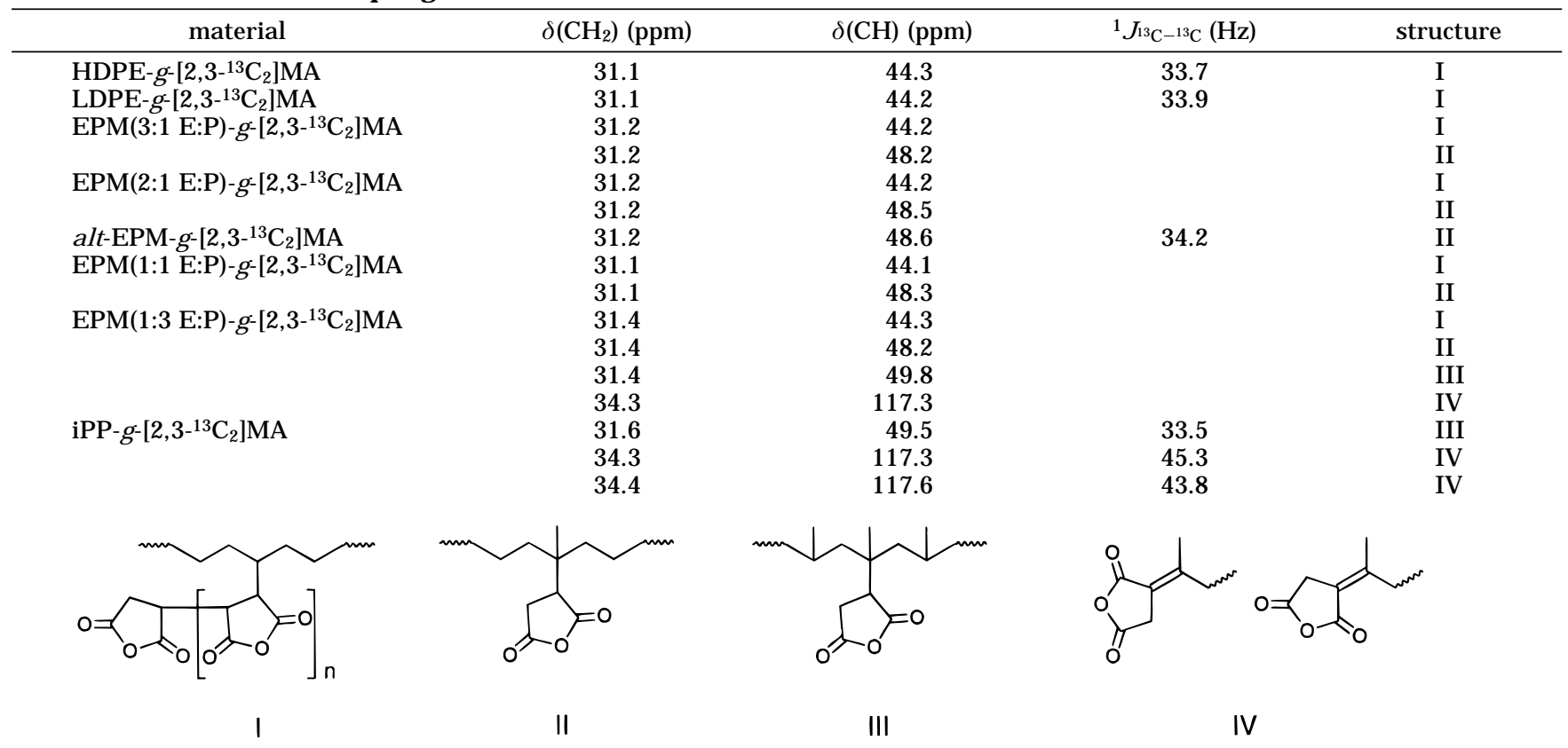

which $2 n+1$ are methines, for $n+1$ MA rings in the graft (see structure I in Table 1). The ${ }^{13} \mathrm{C}$ labels then give rise to a broad complex pattern due to the large number of J couplings, the occurrence of diastereometry, and the fact that the methine carbons have a small dispersion in chemical shifts. A signal at $\delta=44-45$ ppm should indeed arise from oligomeric grafts, taking into account that the chemical shift of the methines in poly(MA) is about 45 ppm. ${ }^{27}$

Figure 2 shows the inadequate data for the various polyol efins grafted with $\left[2,3-{ }^{13} \mathrm{C}_{2}\right] \mathrm{MA}$ at $170{ }^{\circ} \mathrm{C}$, either in the melt or in solution. The spectra are shown in magnitude mode for optimal visual clarity. They are placed in top-to-bottom order of decreasing $E: P$ ratio, with the spectrum of each material grafted in solution bel ow that of the same substrate grafted in the melt. Apparently, smaller amounts of $\left[2,3^{-13} \mathrm{C}_{2}\right] \mathrm{MA}$ have grafted onto the polymer backbone in the melt-grafting experiments. For example, from the integrated responses it can be estimated that about 4 wt \% $\left[2,3-{ }^{13} \mathrm{C}_{2}\right] \mathrm{MA}$ has grafted onto HDPE in solution and about $1 \mathrm{wt} \%$ in the melt-grafting experiment. For alt-EPM these numbers are about 3 wt $\%$ and about $3 \times 10^{-1}$ wt $\%$, respectively. In the melt-grafted materials small residual peaks are observed due to incompl ete double quantum filtering in the inadequate experiment and/or natural abundance spin pairs. These signals, in Figure 2 marked with an asterisk, are easily recognized by comparing the inadequate spectra with the noise-decoupled ${ }^{13} \mathrm{C}$ spectra and can be assigned according to published data. 28,29 In the spectrum of solution-grafted HDPE (Figure 2b), the expected response of the backbone methylenes at $\delta=$ 29.8 is invisibly small relative to label signals due to high levels of grafted $\left[2,3-{ }^{13} \mathrm{C}_{2}\right] \mathrm{MA}$.

The LDPE is a copolymer of 1-octene (25 wt \%) and ethene, and therefore it has as many tertiary carbon atoms in its chain as an EPM with a molar $E: P$ ratio of $12: 1$. From the similarity of the signals at $\delta \approx 31.1$ and $\delta \approx 44.3 \mathrm{ppm}$ in the three PE spectra (Figure $2 \mathrm{a}-\mathrm{c}$ ) it is evident that MA attaches to similar sites in LDPE and HDPE, obviously extended polymethylene $\left(\mathrm{CH}_{2}\right)_{n}$ sequences, in the form of both single anhydride rings and (short) oligomers, as represented by structure I in Table 1 . Since the solution-grafted HDPE has been thoroughly extracted with boiling acetone, a good solvent for polyMA, ${ }^{27}$ it can be excluded that part of the label signals stem from oligo-MA that is not attached to $P E$. The overall mechanism of the grafting reaction is depicted in Figure 3.

From the integrated label signals in the noise-decoupled spectra of the grafted PEs, the values for $n$ in structure I (Table 1) are estimated to be $0.8 \pm 0.1$ for HDPE grafted in the melt, $0.11 \pm 0.01$ for HDPE grafted in solution, and $0.30 \pm 0.02$ for melt-grafted LDPE. These values therefore indicate an average of about four dimeric grafts per every single graft for melt-grafted HDPE. Analogously, we deduce that there is an average of one dimeric graft per ten single ring grafts for solution-grafted HDPE and one dimeric graft per three monomeric units for melt-grafted LDPE. The higher values in the melt-grafting experiments can possibly be attributed to local high MA concentrations, due to limited solubility of MA in the polymer, which might favor MA homopolymerization. The predominance of single anhydride grafts in melt-grafted LDPE, when compared to melt-grafted HDPE, can probably be explained by the presence of some readily transferrable tertiary hydrogen atoms on the polymeric chain of LDPE, which can terminate the grafting reaction (vide infra). The width of the label responses in solutiongrafted HDPE, in which predominantly single rings are present, and the absence of a prominent, neat $A B$ pattern indicate that there is some dispersion in chemical shifts. For instance, clustering of grafts on the backbone caused by grafting of MA onto radical sites formed by intramolecular hydrogen abstraction by an appending succinyl radical may give rise to dispersed label signals. In contrast, for LDPE-g-MA, the relatively large width of the label responses could be simply associated with the many chemically different grafting sites on the backbone. Recently, Russell ${ }^{18}$ attributed the formation of oligomeric grafts during the radically initiated reaction between MA and low molecular weight aliphatic model compounds in solution at 60 and $80^{\circ} \mathrm{C}$ to the fact that the reaction was carried out below the ceiling temperature of MA polymerization, which is estimated to be $108{ }^{\circ} \mathrm{C}$ for $1 \mathrm{M}$ and $90{ }^{\circ} \mathrm{C}$ for $0.4 \mathrm{M}$ monomer concentration. ${ }^{18}$ However, since we find 


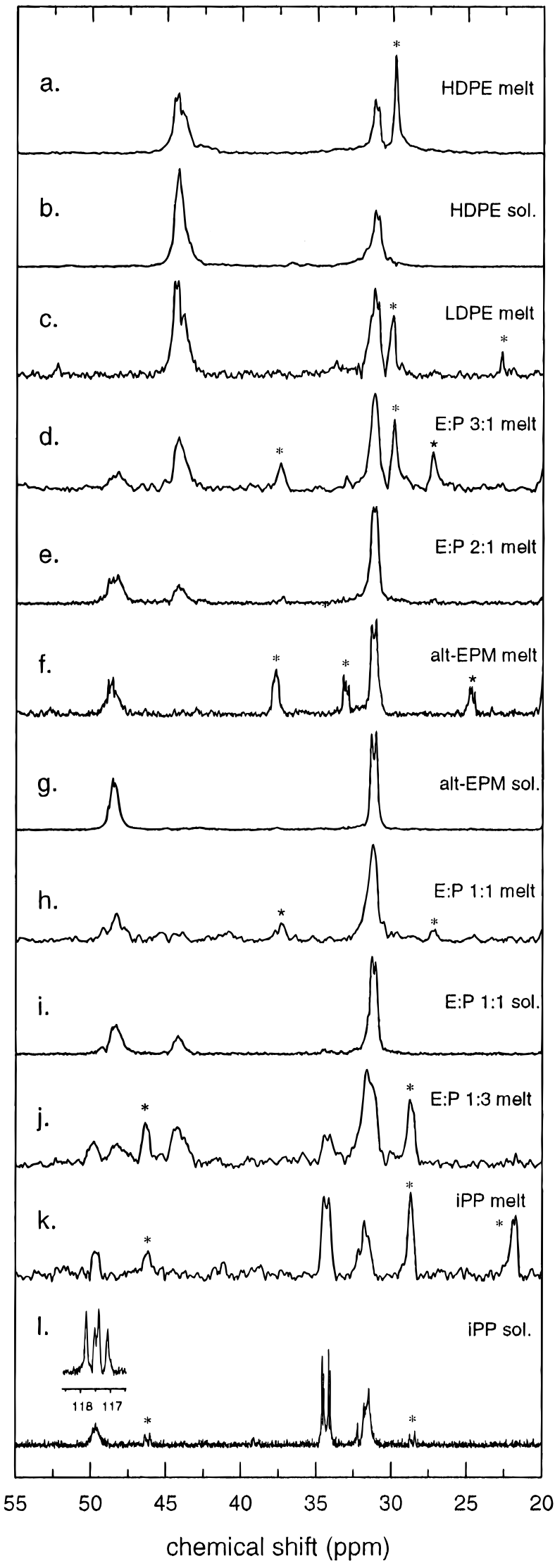

Figure 2. Magnitude-calculated inadequate spectra of $P E$, $P P$, and EPM grafted with $\left[2,3^{-13} \mathrm{C}_{2}\right] \mathrm{MA}$ at $170^{\circ} \mathrm{C}$ in the melt and in solution. $E: P$ (equivalent) ratio of the copolymer: (a) 1:0 (HDPE, melt); (b) 1:0 (HDPE, solution); (c) 12:1 (LDPE, 25 wt \% octene, random, melt); (d) 3:1 (random, melt); (e) 2:1 (random, melt); (f) 1:1 (hydrogenated alt-EPM, melt); (g) 1:1 (hydrogenated alt-EPM, solution); (h) 1:1 (random, melt); (i) 1:1 (random, solution); (j) 1:3 (random, melt). Residual responses from unlabeled sites are marked with an asterisk. significant amounts of dimeric or oligomeric grafts in $\left[2,3-{ }^{13} \mathrm{C}_{2}\right] \mathrm{MA}$-grafted PEs prepared in either the melt or in solution at $170^{\circ} \mathrm{C}$, our experiments do not provide support for a clear correlation between ceiling temperature and the occurrence of oligomeric grafts.

Structure of E PM-g-MA. In the spectra of the meltgrafted 3:1 and 2:1, and the solution-grafted 1:1 E:P random EPMs (Figure 2d,e,i, respectively) signals from labeled sites are found at the same chemical shifts as in the spectrum of grafted HDPE. Hence, these signals are attributed to the same structure as in HDPE-g-[2,3${ }^{13} \mathrm{C}_{2}$ ]MA (structure I in Table 1). The corresponding signal cannot be observed in the spectrum of meltgrafted random 1:1 E:P copolymer (Figure $2 \mathrm{~h}$ ), but this is most probably due to a low degree of grafting in the melt in this material.

The spectra of the melt-grafted $3: 1$ and $2: 1 \mathrm{E}: P$ random copolymers (F igure 2d,e, respectively), the meltgrafted alt-EPM (Figure 2f), the solution-grafted altEPM (Figure $2 \mathrm{~g}$ ), and the melt- and solution-grafted random 1:1 EP copolymers (Figure $2 \mathrm{~h}, \mathrm{i}$, respectively) show a signal at $\delta=48.6 \mathrm{ppm}$. This is close to the chemical shift of the methine of the anhydride ring $(\delta$ $=47.9 \mathrm{ppm}$ ) in the model compound (4-methylhept-4$\mathrm{yl}$ )succinic anhydride. ${ }^{26}$ Therefore, this signal should arise from the methine group in succinic anhydride rings formed by the attachment of $\left[2,3-{ }^{13} \mathrm{C}_{2}\right] \mathrm{MA}$ to tertiary radicals on the polymer chain, as represented by structure II in Table 1 . Since there is no response present at $\delta \approx 45 \mathrm{ppm}$ in the spectrum of alt-EPM-g$\left[2,3-{ }^{13} C_{2}\right] \mathrm{MA}$ grafted in either the melt or solution, which could be attributed to the methine in a succinic anhydride ring attached to a methylene, our results demonstrate that MA attaches predominantly to the tertiary carbon atoms of the alt-E PM backbone and that it attaches in the form of single anhydride rings, since oligomeric structures would have caused an additional response about $\delta=45 \mathrm{ppm}$. The mechanism of grafting MA onto the random EPMs discussed above appears to be a combination of that of PE and alt-EPM, which are given in Figure 3. The responses from the methylene carbons in the anhydride rings attached to the various sites in EPM all coincide at $\sim 31 \mathrm{ppm}$.

Structure of iPP-g-MA and P-Rich EPM-g-MA. Figure 2l shows parts of the inadequate spectrum of iPP grafted in solution. It contains a signal at $\delta=31.6 \mathrm{ppm}$ and a broader signal at $\delta=49.5 \mathrm{ppm}$. These are likely from single succinic anhydride rings that are formed when $\left[2,3-{ }^{13} \mathrm{C}_{2}\right] \mathrm{MA}$ reacts with a tertiary radical site on the iPP backbone (structure III in Table 1). The methine of the anhydride ring in iPP-g- $\left[2,3-{ }^{13} \mathrm{C}_{2}\right] \mathrm{MA}$ resonates at somewhat lower field when compared to the one in alt-E PM-g-[2,3-13 $\left.\mathrm{C}_{2}\right] \mathrm{MA}(\delta=48.6 \mathrm{ppm})$, most probably due to the proximity of methyl groups on the iPP backbone. De Roover et al. ${ }^{17}$ reported that PP-gMA contains oligomeric or even polymeric grafts, exclusively attached to the chain ends of PP. However, such graft structures should give rise to signals at $\delta \approx$ $45 \mathrm{ppm}$, which are not observed in our spectra (Figure $2 \mathrm{k}, \mathrm{I})$. Hence, in our opinion, the mechanism as proposed by Gaylord, ${ }^{7}$ describing the formation of oligomeric graft structures in PP-g-MA, is definitely not unique and is of minor importance for high-temperature PP grafting. In addition, the presence of single anhydride rings attached to the PP chain end, formed by the addition of MA to secondary radicals produced by $\beta$-scission of iPP, can be excluded, taking into account that the chemical shift of the ring methine in the model compound (4'methyl pent-2'-yl)succinic anhydride is about 45.8 ppm. ${ }^{26}$ 
Grafting onto PE (-sequences):

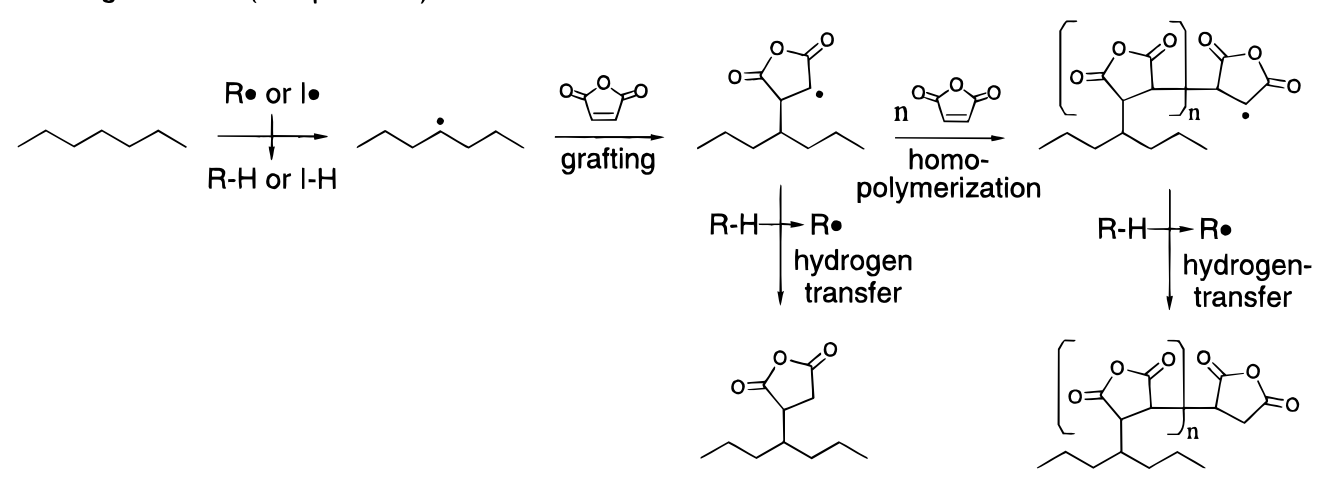

Grafting onto alt-EPM (-sequences):

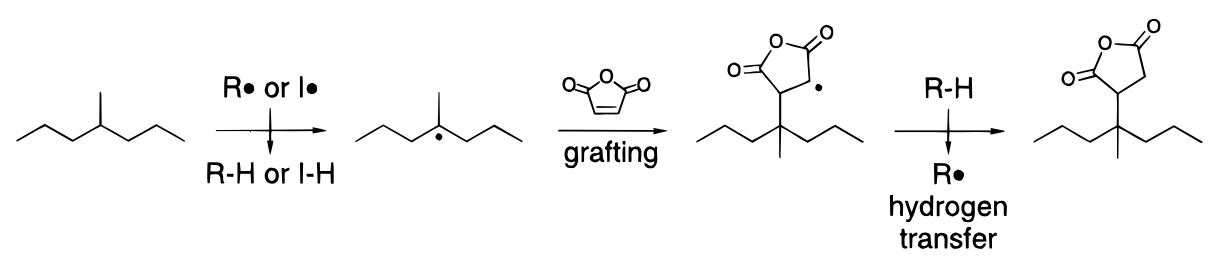

Grafting onto iPP (-sequences):

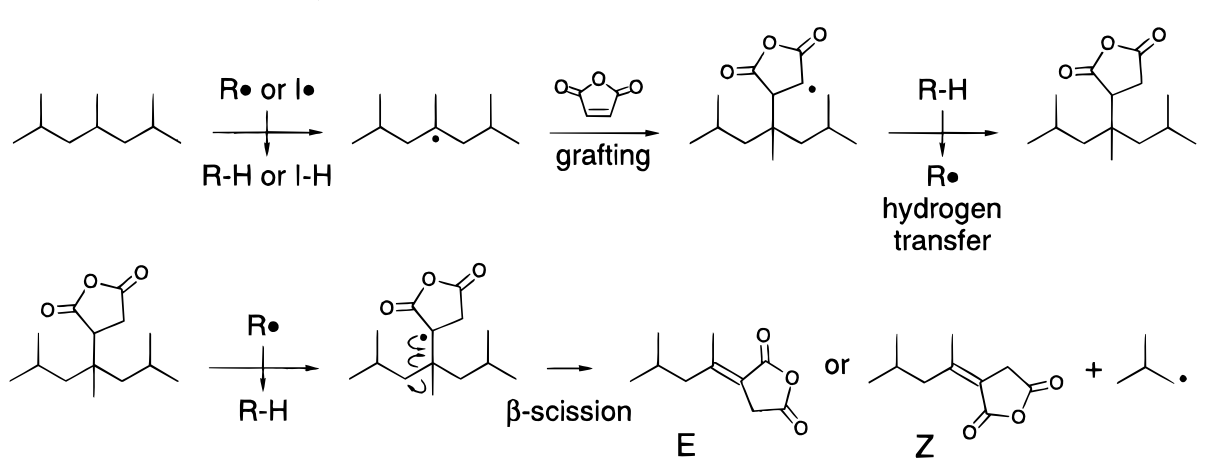

Figure 3. Proposed mechanisms for the grafting of $M A$ onto $P E$, alt-EPM, and iPP, and onto corresponding structures in copolymers. $1 \cdot$ represents an initiator radical, $\mathrm{R}$ a polymer chain, and $\mathrm{R} \cdot$ a macroradical.

The spectrum in Figure 21 shows two pairs of doublets centered at $\delta \approx 34.3 \mathrm{ppm}$, in the spectral region of aliphatic carbons, and at $117.5 \mathrm{ppm}$, in the ol efin region. Each doublet in both pairs has a splitting matching that of a doublet in the other pair, the values being 43.8 and $45.3 \mathrm{~Hz}$, which are normal values for splittings caused by a one-bond J cc coupling. ${ }^{25}$ Two very similar, isomeric graft structures, with $E$ and $Z$ configurations around a double bond, can be formed when chain scission occurs near the site of attachment of an anhydride ring, which would explain the observation of two sets of corresponding doublets at similar chemical shifts (structure IV in Table 1). This mechanism, depicted in Figure 3, resembles the one describing the $\beta$-scission in PP, with the marked difference that in the present case a primary radical and a fully substituted double bond are finally created, while in the PP $\beta$ chain scission mechanism a secondary radical and a methylidene double bond are formed. The spectrum of iPP grafted in the melt ( $F$ igure $2 \mathrm{k}$ ) shows weak responses from label ed sites at the same chemical shifts as in the spectrum of solution-grafted iPP, revealing that in this material $\left[2,3-{ }^{13} \mathrm{C}_{2}\right] \mathrm{MA}$ grafts to the same sites.

Figure 4 shows the aliphatic part of a 2D-J -resolved spectrum of iPP $-\mathrm{g}-\left[2,3^{13} \mathrm{C}_{2}\right] \mathrm{MA}$. The signals at $\delta=34.3$ ppm from the methylene in the anhydride ring pendant from the chain terminus by a double bond are two triplets due the combined effect of homonuclear ${ }^{13} \mathrm{C} \mathrm{J}$ coupling and heteronuclear coupling with the protons directly attached to this carbon atom. The triplets are shifted in the J domain with respect to each other due to the ${ }^{1} \mathrm{H}-{ }^{13} \mathrm{C}$ J coupling. It can be concluded that no proton is attached to the double bond, since this would cause a further splitting, which is not observed. This supports the proposed structure IV (Table 1), and hence the proposed mechanism as depicted in Figure 3.

The spectrum of the 1:3 E:P EPM (Figure 2j) shows resonances at the same chemical shifts as the signals from the labeled sites in HDPE-g-[2,3- $\left.{ }^{13} \mathrm{C}_{2}\right] \mathrm{MA}$ (Figure $2 a, b)$, which are attributed to structure (Table 1 ). Two weak resonances at $\delta=48.2$ and $\delta=49.8 \mathrm{ppm}$ can be recognized that are also observed in the data collected from the grafted 1:1 E:P EPM (Figure $2 \mathrm{~h}, \mathrm{i}$ ) and from iPP-g- $\left[2,3-{ }^{13} \mathrm{C}_{2}\right] \mathrm{MA}$ (Figure $2 \mathrm{k}, \mathrm{I}$ ). These signals are therefore attributed to structures II and III (Table 1). The signal at $\delta \approx 34 \mathrm{ppm}$ is attributed to a methylene in a structure similar to that present in iPP-g-[2,3-13 $\left.\mathrm{C}_{2}\right]-$ $M A$, i.e. succinic anhydride attached to a chain terminus by a double bond (structure IV in Table 1). The signal from the adjacent label ed site in the connecting double bond can be found at $\delta=117 \mathrm{ppm}$ (not shown) but is less intense than in the spectrum of iPP-g- $\left[2,3^{-13} \mathrm{C}_{2}\right] \mathrm{MA}$, apparently due to a lower degree of this mode of grafting in this material. In the 1:3 E:P random copol ymer there is a multitude of possible sites of attachment, and the combination of spectral features found in the spectra of HDPE-g- $\left[2,3-{ }^{13} \mathrm{C}_{2}\right] \mathrm{MA}$, alt-EPM-g-[2,3- $\left.{ }^{13} \mathrm{C}_{2}\right] \mathrm{MA}$, and iPP- 


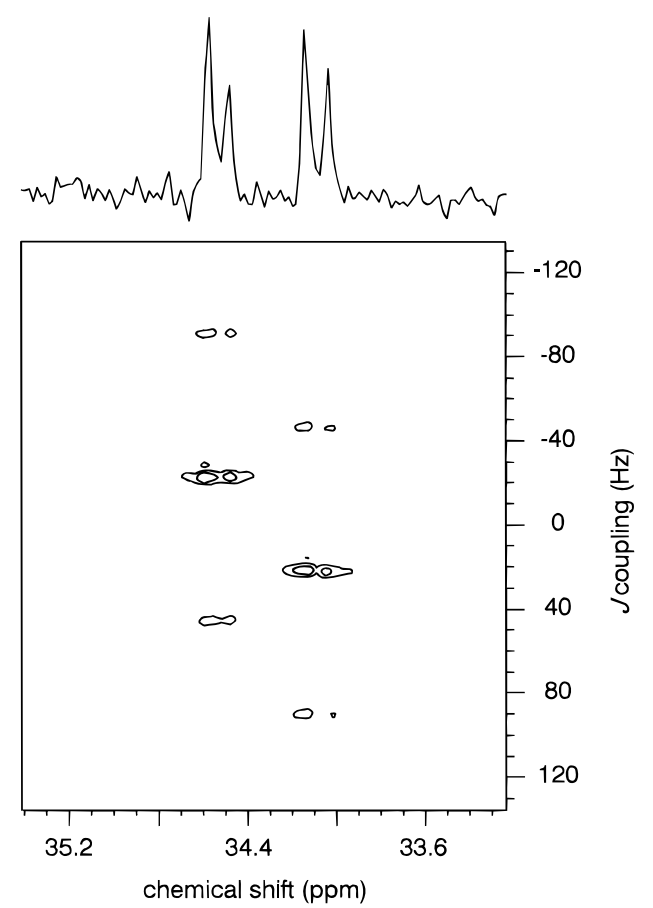

Figure 4. ${ }^{13} \mathrm{C} 2 \mathrm{D}$ J -resolved NMR spectrum of iPP-g- $\left[2,3-{ }^{13} \mathrm{C}_{2}\right]-$ $\mathrm{MA}$. The signal at $\delta=34.3 \mathrm{ppm}$ is split into a triplet due to the presence of two protons attached directly to the corre sponding carbon atom in the terminally attached anhydride ring. $\mathrm{No}^{3}{ }^{1} \mathrm{H}-{ }^{13} \mathrm{C}$ coupling is observed.

$\mathrm{g}-\left[2,{ }^{-13} \mathrm{C}_{2}\right] \mathrm{MA}$ is observed in the spectrum of this material.

The spectroscopic results and assignments are summarized in Table 1.

General Remarks. The highly resolved, noise decoupled ${ }^{13} \mathrm{C}$ NMR spectra of solution-grafted alt-E PM and IPP (data not shown) reveal a neat doublet at $\delta \approx$ $31.4 \mathrm{ppm}$ and a broader signal at $\delta=48-50 \mathrm{ppm}$. A similar response is less resolved in the 1D inadequate spectra (Figure 2g,l, respectively). The fact that the lowfiel d signals in these spectra do not comprise single neat doublets, while MA attaches as single succinic anhydride rings, must be attributed to atacticity in the polymer backbone. In alt-EPM this is introduced by the nonspecific hydrogenation, in iPP probably by the action of the peroxide initiator: after hydrogen abstraction from a tertiary carbon atom in iPP, the specific orientation around that atom is lost.

From the pronounced presence of methylene carbon signals from succinic anhydride structures I, II , and III (Table 1), all at $\delta \approx 31$ ppm in the spectra in Figure 2, it is evident that termination of the succinyl radicals, present after addition of MA to a macroradical, or to a succinyl radical in the case of MA oligomerization, takes place by transfer of hydrogen atoms from polymer chains. The absence of oligomeric graft structures in EPMs of low E:P ratio can consequently be explained by the abundance of easily transferrable tertiary hydrogen atoms in these materials. The generation of macroradicals by the hydrogen transfer to succinyl radicals, which are new sites available for grafting reactions, signifies that more than one $M A$ can be grafted per single initiator radical, as has been noted before. ${ }^{16}$

Intramolecular hydrogen transfer, involving a sixmembered ring transition state, can in principle terminate the grafting reaction. However, in that case the succinyl radical, formed by the addition of a MA monomer to a tertiary radical on the alt-E PM backbone, should abstract a hydrogen atom from a secondary carbon atom in the backbone, creating a secondary radical. Since MA grafts readily onto secondary radicals, as in the case of PE, and no signals attributable to MA grafted onto a secondary backbone radical are observable in the spectrum of alt-EPM-g-MA, we conclude that there are no or few secondary radicals present in alt-EPM during radically initiated grafting of $M A$, and hence terminative hydrogen transfer from methine carbons does not involve a six-membered ring transition state. This is corroborated by the observation that in PE oligomeric grafts are present, while grafts occur solely as single rings in MA-grafted alt-EPM. Apparently, when radically initiated MA grafting is performed in either the melt or solution, the MA oligomerization and hydrogen transfer from methylenes proceed at similar rates, while hydrogen transfer from methine carbons proceeds faster than both.

The spectra of the materials grafted in the melt or the solution processes are very similar. This indicates that the structure and the sites of attachment of the grafts are largely independent of the method of functionalization. The major difference between the two methods is the higher level of grafted $\left[2,3-{ }^{13} \mathrm{C}_{2}\right] \mathrm{MA}$ in the products from the solution process, but this can easily be rationalized by considering the larger MA to polyol efin ratio and the longer reaction times used there. Finally, we find no indication for MA acting as a crosslinker between two polymer chains, in the form of a single anhydride ring, as has been suggested. ${ }^{8}$ The overall mechanism accurately describing the grafting of MA onto polyolefins is depicted in Figure 3.

\section{Conclusion}

The structure of polyolefins grafted with MA in a melt and a solution process at $170^{\circ} \mathrm{C}$ has been elucidated by ${ }^{13} \mathrm{C}$ NMR spectroscopy in conjunction with specific isotope labeling of MA. By placing two adjacent ${ }^{13} \mathrm{C}$ labels in the MA monomer, the inadequate technique can be successfully applied to suppress the intense resonances corresponding to the carbon atoms in the polymer backbone, thus showing only the signals of main interest when studying the grafting process.

MA attaches to the HDPE and LDPE in the form of single succinic anhydride rings as well as short oligomers. In (co)polymers with abundant tertiary hydrogen atoms, such as alt-EPM and iPP, MA grafts onto the polymer backbone chiefly in the form of single succinic anhydride rings. Polymethylene sequences $\left(\mathrm{CH}_{2}\right)_{\mathrm{m}}$ with $\mathrm{m}>3$ are needed to allow grafting of MA onto a backbone methylene. In (co)polymers with high $\mathrm{P}$ content, i.e. iPP and 1:3 E:P copolymers, a chain scission reaction can occur, yielding an anhydride ring attached to the chain terminus via a double bond.

The structure and the site of attachment of the graft do not appear to depend on the method of functionalization, either in solution or under melt conditions. No evidence is found for MA acting as a cross-linking agent.

Acknowledgment. The support and assistance of C. Erkelens, J . Beulen, M. Bulters, P. Elemans, and T. Veermans during various stages of this work are gratefully acknowledged.

\section{References and Notes}

(1) Greco, R.; Malinconico, M.; Martuscelli, E.; Ragosta, G.; Scarinzi, G. Polymer 1987, 28, 1185.

(2) Hobbs, S. Y.; Bopp, R. C.; Watkins, V. H. Polym. Eng. Sci. 1983, 23(7), 380. 
(3) Padwa, A. R. Polym. Eng. Sci. 1992, 32, 1703.

(4) Duvall, J .; Sellitti, C.; Myers, C.; Hiltner, A.; Baer, E. J . Appl. Polym. Sci. 1994, 52, 195.

(5) Majumdar, B.; Keskkula, H.; Paul, D. R. Polymer 1994, 35, 1386.

(6) Gaylord, N. G.; Mehta, M.; Kumar, V. Org. Coat. Appl. Polym. Sci. Proc. 1981, 46, 87.

(7) Gaylord, N. G.; Mishra, M. K. J . Polym. Sci., Polym. Lett. Ed. 1983, 21, 23.

(8) Gaylord, N. G.; Mehta, M. J . Polym. Sci., Polym. Lett. Ed. 1982, 20, 481.

(9) Trivedi, B. C.; Culbertson, B. M. Maleic Anhydride; Plenum Press: New York, 1982

(10) ReactiveExtrusion - principles and practice; Hanser Publishers: Munich, 1992.

(11) Gabara, W.; Porejko, S. J . Polym. Sci., Polym. Chem. Ed. 1967, 5, 1547.

(12) Liu, N. C.; Baker, W. E.; Russell, K. E. J . Appl. Polym. Sci. 1990, 41, 2285.

(13) Braun, D.; Eisenlohr, U. Angew. Makromol. Chem. 1976, 55, 43.

(14) Cimmino, S.; d'Orazio, L.; Greco, R.; Maglio, G.; Malinconico, M.; Mancarella, C.; Martuscelli, E.; Palumbo, R.; Ragosta, G. Polym. Eng. Sci. 1984, 24, 48.

(15) Gaylord, N. G.; Mehta, M.; Mehta, R. J . Appl. Polym. Sci. 1987, 33, 2549.

(16) Russell, K. E.; Kelusky, E. C. J . Polym. Sci., Part A: Polym. Chem. 1988, 26, 2273.
(17) Deroover, B.; Sclavons, M.; Carlier, V.; Devaux, J .; Legras, R.; Momtaz, A. J . Polym. Sci., Part A: Polym. Chem. 1995, 33, 829.

(18) Russell, K. E. J . Polym. Sci., Part A: Polym. Chem. 1995, $33,555$.

(19) Tonelli, A. E. NMR Spectroscopy and Polymer Microstructure: the Conformational Connection; VCH Publishers: New York, 1989.

(20) Glans, J . H.; Akkapeddi, M. K. Macromolecules 1991, 24, 383.

(21) Bestmann, H. J .; Kisielowski, L.; Distler, W. Angew. Chem. 1976, 88, 297.

(22) Priola, A.; Bongiovanni, R.; Gozzelino, G. Eur. Polym. J . 1994, 30, 1047.

(23) Wu, C. J .; Chen, C. Y.; Woo, E. M.; Kuo, J . F. J . Polym. Sci., Part A: Polym. Chem. 1993, 31, 3405.

(24) Bax, A.; Freeman, R.; Kempsell, S. P. J . Am. Chem. Soc. 1980, $102,4849$.

(25) Breitmaier, E.; Voelter, W. Carbon-13 NMR Spectroscopy High Resolution Methods and Application in Organic and Biochemistry; VCH: Weinheim, 1987.

(26) Heinen, W.; Erkens, S. W.; Lugtenburg, J .; Van Duin, M. Manuscript In preparation.

(27) Regel, W.; Schneider, C. Makromol. Chem. 1981, 182, 237.

(28) Van der Velden, G. Macromolecules 1983, 16, 85.

(29) Carman, C. J .; Harrington, R. A.; Wilker, C. E. Macromolecules 1977, 10, 536.

MA951015Y 